\title{
Decontamination of breast pump milk collection kits and related items at home and in hospital: guidance from a Joint Working Group of the Healthcare Infection Society \& Infection Prevention Society*
}

Journal of Infection Prevention

2016, Vol. 17(2) 53-62

DOI: $10.1|77 /| 757|774| 56 \mid 3566$

(C) The Author(s) 2015

Reprints and permissions:

sagepub.co.uk/journalsPermissions.nav

jip.sagepub.com

@SAGE

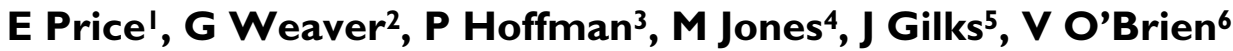 \\ and G Ridgway (Chairman) ${ }^{7}$
}

\begin{abstract}
Introduction: A variety of methods are in use for decontaminating breast pump milk collection kits and related items associated with infant feeding. This paper aims to provide best practice guidance for decontamination of this equipment at home and in hospital. It has been compiled by a joint Working Group of the Healthcare Infection Society and the Infection Prevention Society.

Methods: The guidance has been informed by a search of the literature in Medline, the British Nursing Index, the Cumulative Index to Nursing \& Allied Health Literature, Midwifery \& Infant Care and the results of two surveys of UK neonatal units in 2002/3 and 2006, and of members of the Infection Prevention Society in 2014. Since limited good quality evidence was available from these sources much of the guidance represents good practice based on the consensus view of the Working Group.
\end{abstract}

\section{Key recommendations:}

- Breast pump milk collection kits should not be reused by different mothers unless they have been sterilized in a Sterile Services Department between these different users.

- When used by the same mother, a detergent wash followed by thorough rinsing and drying after each use gives acceptable decontamination for most circumstances, as long as it is performed correctly.

- Additional decontamination precautions to washing, rinsing and drying may be used if indicated by local risk assessments and on advice from the departmental clinicians and Infection Prevention and Control Teams. The microbiological quality of the rinse water is an important consideration, particularly for infants on neonatal units.

- If bottle brushes or breast/nipple shields are used, they should be for use by one mother only. Decontamination should be by the processes used for breast pump milk collection kits.

- Dummies (soothers, pacifiers or comforters) needed for non-nutritive sucking by infants on neonatal units, should be for single infant use. Manufacturers should provide these dummies ready-to-use and individually packaged. They

\footnotetext{
"This paper is published simultaneously in the Journal of Infection Prevention and the Journal of Hospital Infection (journalofhospitalinfection.com, DOI: $10.1016 / j$.jhin.2015.08.025). The Editors of the Journals have agreed that joint publication of the article is justified to ensure dissemination of the guidance to all relevant healthcare professionals.
}

\footnotetext{
'Honorary Consultant Microbiologist, Department of Infection, Barts Health NHS Trust, London, UK

${ }^{2}$ Human Milk Bank Manager, The Milk Bank, Imperial College Healthcare NHS Trust, London, UK

${ }^{3}$ Consultant Clinical Scientist, Antimicrobial Resistance and Healthcare-associated Infections Reference Unit, Public Health England, London, UK

${ }^{4}$ Infection Prevention and Control Matron, Liverpool Community Health, Liverpool, UK

${ }^{5}$ Former Clinical Nurse Specialist for Infant Feeding, Barts Health NHS Trust, London, UK

${ }^{6} \mathrm{Global}$ Technical Lead, Synergy Health, Manchester, UK (Representing the Institute of Decontamination Sciences)

${ }^{7}$ Consultant Clinical Microbiologist (retired), Ringwood, Hampshire, UK
}

Corresponding author:

E Price, Department of Infection, Barts Health NHS Trust, Pathology and Pharmacy Building, London, EI 2ES, UK.

Email: elizabethshanson@btinternet.com 
must be discarded at least every 24 hours or immediately if soiled with anything other than the baby's saliva. No attempt should be made to decontaminate the dummies, either before or during use.

Conclusion: This guidance provides practical recommendations to support the safe decontamination of breast pump milk collection kits for healthcare professionals to use and communicate to other groups such as parents and carers.

\section{Keywords}

breast pump milk collection kits, decontamination, atmospheric pressure steam, hypochlorite based chemical disinfectants, dummies (pacifiers, comforters or soothers), bottle brushes, breast/nipple shields

Date received: 20 April 2015; accepted: 25 August 2015

\section{Background}

Breast pump milk collection kits are not classified as medical devices within the meaning of the Medical Devices Directive 93/42/EEC and there is no legal requirement for manufacturers to provide detailed instructions on their decontamination. A variety of processes may be used to decontaminate the kits but all of them have some drawbacks or risks (Doxtator and Zoutman, 2006; Gilks et al., 2007, 2012). Also, the levels of decontamination required may vary according to a number of circumstances.

These considerations have presented difficulty with formulating guidance for decontamination of breast pump milk collecting kits. A joint Working Group of the Healthcare Infection Society (HIS) and the Infection Prevention Society (IPS) was convened to review this problem. The Working Group also considered the decontamination of some related items associated with infant feeding, including bottle brushes and breast/nipple shields. The decontamination of dummies (pacifiers, comforters or soothers), for use by some infants on Neonatal Units (NNUs) for non-nutritive sucking, was also reviewed.

\section{Aims and target groups}

This paper aims to provide best practice guidance on the cleaning and decontamination of breast pump milk collection kits and some related items associated with infant feeding, in hospital and at home. The prime target groups for this guidance are professional groups including neonatal and midwifery nursing staff, infection prevention and control nursing staff and microbiologists. The next target group is the infant's parents and/or carers who should be reached through the professional groups mentioned.

\section{Methods}

This guidance was written by a joint Working Group of the HIS and the IPS. Membership of the multi-professional Working Group included clinical microbiologists, a clinical scientist, a neonatal nurse, an infection control nurse practitioner, a sterile services advisor and a breast milk bank expert.

\section{Definitions}

The Working Group used the following definitions:

Decontamination is any process that renders an item safe and fit for reuse; it will always involve cleaning and may involve disinfection and/or sterilization.

Sterilization is rendering an item free from micro-organisms with a very high level of quality assurance.

Disinfection is a process resulting in a reduction in the number of infectious agents to a level considered safe.

Cleaning is a process that entails physical removal of microorganisms and anything else that is not part of an item.

\section{Decontamination methods available for Working Group consideration}

- Single use only, where new disposable sterile equipment is provided for every use.

- Washing in warm water with detergent, rinsing thoroughly, drying and storing the equipment dry.

- Washing and rinsing followed by an additional decontamination method:

- Production of atmospheric pressure steam by heating tap water either in a free standing electrical unit, or inside bags or lidded bowls placed in a microwave oven.

- Immersion in hypochlorite-based chemical disinfectants. There are two main sources of hypochlorite: liquid sodium hypochlorite or solid (tableted) sodium dichloroisocyanurate (NaDCC). See further comments on this method below under 'Chemical disinfection'.

These additional decontamination methods could be used at home as well as in hospital, either because the mother has 
Table I. Breast pump milk collection kits - percentage use of various decontamination methods.

\begin{tabular}{|c|c|c|c|c|c|c|}
\hline $\begin{array}{l}\text { Survey date } \\
\text { and number } \\
\text { of units taking } \\
\text { part }\end{array}$ & $\begin{array}{l}\text { Immersion in } \\
\text { hypochlorite } \\
\text { based disinfectant } \\
\text { after each use }\end{array}$ & $\begin{array}{l}\text { Atmospheric } \\
\text { pressure } \\
\text { steam after } \\
\text { each use }\end{array}$ & $\begin{array}{l}\text { Detergent wash } \\
\text { rinse \& dry } \\
\text { after each use }\end{array}$ & $\begin{array}{l}\text { Discard } \\
\text { after } \\
\text { each use }\end{array}$ & $\begin{array}{l}\text { Sterilize in a Sterile } \\
\text { Services Department } \\
\text { after each use }\end{array}$ & $\begin{array}{l}\text { Other, including } \\
\text { dish-washing } \\
\text { machines }\end{array}$ \\
\hline $\begin{array}{l}2002 / 3 \\
\text { (7I units) }\end{array}$ & $\begin{array}{l}61 \% \\
\text { (43 units) }\end{array}$ & $\begin{array}{l}27 \% \\
\text { (19 units) }\end{array}$ & $\begin{array}{l}0 \% \\
(0 \text { units })\end{array}$ & $\begin{array}{l}7 \% \\
\text { (5 units) }\end{array}$ & $\begin{array}{l}0.7 \% \\
\text { (I unit) }\end{array}$ & $\begin{array}{l}4 \% \\
\text { (3 units) }\end{array}$ \\
\hline $\begin{array}{l}2006 \\
\text { (25 units) }\end{array}$ & $\begin{array}{l}56 \% \\
\text { (14 units) }\end{array}$ & $\begin{array}{l}16 \% \\
\text { (4 units) }\end{array}$ & $\begin{array}{l}4 \% \\
\text { (1 unit ) }\end{array}$ & $\begin{array}{l}8 \% \\
\text { (2 units) }\end{array}$ & $\begin{array}{l}16 \% \\
\text { (4 units) }\end{array}$ & $\begin{array}{l}\text { Nil } \\
\text { (0 units) }\end{array}$ \\
\hline $\begin{array}{l}20 \mid 4^{*} \\
\text { (26 units) }\end{array}$ & $\begin{array}{l}35 \% \\
\text { (9 units) }\end{array}$ & $\begin{array}{l}19 \% \\
\text { (5 units) }\end{array}$ & $\begin{array}{l}41 \% \\
\text { (I I units) }\end{array}$ & $\begin{array}{l}8 \% \\
\text { (2 units) }\end{array}$ & $\begin{array}{l}4 \% \\
\text { (I unit) }\end{array}$ & $\begin{array}{l}4 \% \\
\text { (I unit) }\end{array}$ \\
\hline
\end{tabular}

*In the 2014 survey, some units used more than one method of decontamination for breast pump milk collection kits.

an infant in hospital and is expressing milk at home, or because she wishes to use an additional method as an extra precaution.

\section{Sources of information used in development of the guidance}

Literature review. A review of the literature was carried out using Medline, the British Nursing Index, the Cumulative Index to Nursing and Allied Health Literature and Midwifery and Infant Care. Subject headings included breast pumps, infants and decontamination, dummies (soothers, pacifiers or comforters). The Working Group concluded from the literature review that although a number of different methods were being used for decontaminating breast pump milk collecting kits when reused by one mother, the information available was limited and sometimes conflicting.

Surveys of current decontamination practices in UK hospitals. The Working Group had access to the results of two surveys conducted in the past 15 years.

During 2002/3, Price and Hateley (E Price \& P Hateley, personal communication) conducted a postal survey of 73 randomly chosen UK NNUs. Seventy one (97\%) units returned the completed questionnaire. In 2006, Shetty et al., carried out a telephone survey on the decontamination of breast pump milk collection kits in 25 tertiary NNUs across the UK.

In 2014, as a preliminary to this report, the Working Group commissioned an on-line survey on behalf of the HIS and the IPS. The survey was advertised in the IPS President's Weekly Digest 6.12.2013 - 27.01.2014. Twenty-six IPS members completed a questionnaire with regard to decontamination of breast pump milk collection kits and related equipment on their units (and also for some community services).

\section{Summary of the findings of surveys on decontamination practices}

\section{General points}

In the $2002 / 3$ survey, $75 \%$ of the units using a hypochlorite based disinfectant did not rinse the disinfectant off articles following immersion. In the 2014 survey, this fell to $37 \%$ of the units. In the 2014 survey, most of the units who rinsed after immersion used sterile water.

In both the 2002/3 and the 2014 surveys, some units indicated that they used more than one method of decontamination for certain items.

\section{Decontamination of breast pump milk collection kits}

The decontamination methods used for breast pump milk collection kits reported in each of the three surveys are given in Table 1. These show a reduction in the use of hypochloritebased chemical disinfection methods; in the 2002/3 survey, $61 \%$ of units used these methods compared with $35 \%$ in the 2014 survey. There was an increase in the use of the wash, rinse and dry method, which was not used at all in 2002/3, but was the commonest method used in 2014.

\section{Decontamination of bottle brushes}

Information concerning decontamination of bottle brushes was only requested in the 2014 survey. In 7 units (27\%) bottle brushes were not used. The commonest method of decontamination used by the other units (12 units, 46\%) was washing, rinsing and drying the brushes. Five units (19.2\%) discarded the brushes after a single use. The remaining units used either an atmospheric pressure steam method or a hypochlorite based chemical disinfectant method. 


\section{Decontamination of dummies}

Processes for decontamination of dummies were surveyed in the 2002/3 and the 2014 surveys. Use of hypochloritebased chemical methods fell from $76 \%$ in the $2002 / 3$ survey to $58 \%$ in 2014 . Even so, immersion in these chemical disinfectants was still the commonest method in use for decontaminating dummies ( $>55 \%$ of units). No unit washed, rinsed and dried these items in the 2002/3 survey whereas $23 \%$ used this method in 2014 . Use of atmospheric pressure steam was $19.7 \%$ and $11.5 \%$ in $2002 / 3$ and 2014 , respectively. Dummies were discarded after a single use by $17 \%$ of units in the $2002 / 3$ survey compared with $7.7 \%$ in the 2014 survey.

\section{Comment on the survey results}

The relatively small number of units involved in these surveys and the different investigation methods used, makes comparison difficult. However, for breast pump milk collection kits, use of the wash, rinse and dry method has now become more frequent than use of chemical disinfectants. For bottle brushes a variety of method were in use but some units did not use these brushes at all. For neonatal dummies, there was a fall in the number of units using hypochlorite based chemicals but this was still the commonest method in use. Rinsing after immersion of any of the above items in chemical disinfectants was more common in the 2014 survey than in the 2002/3 survey. Even so, rinsing did not occur in over one-third of units reporting in the 2014 survey.

\section{The Guidance}

The detailed recommendations of the Working Group are given in the Appendix to this article. Neither the literature review nor the survey findings provided good quality evidence upon which to base recommendations. For these reasons much of the guidance is based on the consensus views of the Working Group on what represents good practice.

\section{Decontamination of breast pump milk collection kits}

General principles. Kits are usually discarded when no longer required by the mother, but if kits are re-used by a different mother, they must have been re-sterilized in a sterile services department (SSD) (the relevant manufacturer should confirm that SSD steam sterilization is an acceptable method for their kits).

Before using any decontamination method, the Working Group recommends that users should check with the kit manufacturers that the method is compatible with their equipment.

All places where mothers express their milk should have good microbiological quality water. In the home, potable (drinking quality) water should be used for rinsing. See also comments below on the microbiological quality of water under 'Additional decontamination methods' and under 'Chemical disinfection'.

Good hygienic practices are necessary throughout the process of expressing breast milk and include washing hands before starting the procedure (Pittard et al., 1991).

Each mother should have her own breast pump milk collection kit which should not be shared with other mothers.

Breast pump milk collection kits can be moderately complex pieces of equipment as they consist of a number of parts, some of which are quite small and delicate. The kits must be completely dismantled and decontaminated after every use, both to facilitate cleaning and because any part that remains wet could be a source of hazardous bacterial growth for the infant.

Decontaminating the kits is usually carried out by the mother. Clear instructions are necessary using demonstrations and illustrated guidance. This instruction should be given by a member of staff with the appropriate competencies prior to the mother commencing decontamination. This guidance needs to be simple and straightforward.

Before first use in hospital, the kit should ideally be sterile (Royle and Weaver, in press). Before first use at home (and in hospital if not sterile), if kits which are new are not marked as sterile, they should be decontaminated according to the manufacturer's instructions (at minimum detergent washed, thoroughly rinsed, dried and stored dry).

Routine decontamination for kits for reuse by the same mother. The Working Group recommended the simple, straightforward method of detergent washing in warm water, rinsing thoroughly in running water, drying and storing items dry. This gives acceptable decontamination, if performed correctly and is the appropriate decontamination method to use in most circumstances. Mothers should be given instruction on each stage of the procedure. The importance of complete drying of all component parts after washing and rinsing needs to be emphasized (D'Amico et al., 2003).

In the home, well maintained dishwashing machines are an alternative to washing and rinsing. The kits need to be fully dismantled with small parts placed in a suitable perforated container. Extra drying with paper towels is often needed after the process. In hospital, dishwashing machines are not often used for washing breast pump milk collection kits. The use of such a unit based dishwashing machine should be approved for individual mothers by the local Infection Prevention \& Control Team (IPCT). These machines should be regularly maintained.

Additional decontamination methods. Decontamination methods in addition to the wash, rinse and dry process may be needed for items for certain infants on NNUs who have high susceptibility to infection, as determined by the 
departmental clinicians. These extra procedures may also be indicated in situations where there is potential lack of compliance by the parents or carers with basic decontamination procedures. The use of additional methods should be in accordance with the policies formulated by the departmental clinicians and the IPCT. These authorities should also advise on decontamination methods to be used in the home for an infant on a NNU whose mother is expressing her milk at home.

The microbiological quality of the rinse water is also an important consideration for infants on NNUs. The rinse water should be from outlets complying with guidance on Pseudomonas aeruginosa in water for augmented care units (Department of Health, 2013). If this water is not of an acceptable microbiological quality, the Working Group recommends that sterile water should be used.

For kits for reuse by one mother, if an additional method is indicated, the main additional method recommended by the Working Group is a heat method based on the production of atmospheric steam. Heat methods have higher quality assurance than chemical methods for disinfection. However neither atmospheric pressure steam nor chemical disinfection will sterilize the kits. For both heat and chemical methods, thorough washing and rinsing of the items should occur first.

If the use of sterile kits is considered necessary, options include steam sterilization in an SSD, or the purchase of sterile single use equipment.

Heat disinfection. The Working Group considered that atmospheric pressure steam methods are quick and convenient to use, although there is a risk of scalding if manufacturers' instructions are not followed. Microwavable bags are intended to be used by only one mother and the number of times they have been used before needing to be discarded should be monitored. After use, the bags should be left open to air dry or dried using paper towels.

For all decontamination methods involving heat (apart from sterilization in an SSD) water will be present on the kits after completing the process. After any excess water has been shaken off, kits should be thoroughly air dried or dried with paper towels.

In hospital, free standing electrical units or microwavable bowls may be used by more than one mother with a risk that parts of kits belonging to different mothers can be interchanged. The Working Group considered that if these units are used communally, the individual kits should be identified to a particular mother and processed separately each time of use. Water should be completely emptied out of the unit or bowl after each use. When not in use, the equipment should be left clean and dry. If this does not happen and there is a delay before the equipment is used again, bacterial and fungal growth may occur.

For microwave ovens, the correct power setting and cycle duration should be checked.

In hospital, both the microwave ovens and the free standing electrical steam-producing units require regular maintenance. In both, the correct amount of water should be used, as recommended by the manufacturer.

Chemical disinfection. Chemical disinfection has lower quality assurance compared to heat disinfection. Where disinfection of the kits and associated items is necessary, the Working Group recommended that heat disinfection is the method of choice and in hospital chemical disinfection should only be used if the local IPCT has given approval of the method and quality assurance of its use.

The solid, tableted form of the hypochlorite based chemical is very stable on dry storage whilst liquid hypochlorite is unstable and should be stored avoiding excess heat and with care to avoid any extraneous material being introduced into the bulk storage container. Both preparations need correct dilution prior to use. Use of inappropriate containers for making up the disinfectant may increase the possibility of user dilution errors. Also, the importance of not using too much or too little disinfectant should be realized. Concentrations which are too low may increase the risk of microbial survival. Concentrations which are too high may result from the incorrect assumption that if a little disinfectant is 'good', more disinfectant may be better. There may also be a theoretical possibility of toxicity for highly susceptible infants (Lucas, 1977; Price et al., 2006).

These chemical disinfectants can be easily inactivated resulting in the possibility of decontamination failure. This can also occur if incorrect techniques are used, such as inadequate pre-cleaning, failure to fully disassemble equipment, incomplete submerging of articles and "topping-up" of disinfectant tanks instead of washing them out and using fresh disinfectant daily (Atkinson, 2001; Gilks et al., 2012; Gransden et al., 1986; Jones et al., 2001; Moloney et al., 1987; Thom et al., 1970). Use of such chemical disinfectants may also give a false sense of security and distract attention from thorough initial washing (Atkinson, 2001). If they are used on a NNU, 40 or more individual chemical tanks may be needed. As well as giving storage problems, there is a risk that kits belonging to different mothers may become mixed-up.

Hypochlorite based solutions are corrosive to some metals. Also, the smell of these disinfectants may persist on a dummy or teat and infant developmental care recommendations include avoiding unpleasant tastes and odours (Lui et al., 2007). Further work is also needed to determine whether continued regular exposure to disinfectant at an early age could influence the development of the protective normal flora of the skin, mouth and gut (including gut organisms producing vitamins B \& K).

Some manufacturers have included rinsing in their decontamination guidance but others do not recommend it. In the surveys mentioned above, more than a third of units did not rinse disinfectant off equipment after using this method. If items are removed from the disinfectant without rinsing, a small volume of the disinfectant will remain on the surface of the equipment. Colostrum or breast milk may 
be collected in very small volumes (for colostrum this could be 1 or $2 \mathrm{ml}$ or even less). The colostrum or breast milk could become contaminated with disinfectant from the equipment surface and it may be fed directly to the infant. The risk of an adverse effect on the constitution of the milk or on a pre-term infant's digestive system has been raised (Atkinson, 2001). With regard to the latter, many infants on NNUs are now much more premature than in previous years and may be more susceptible to insults involving the gut. However, Vitali et al. (2008) commented that $1-2 \mathrm{ml}$ of the disinfectant remaining will be considerably diluted by milk. They suggested that feeds of $40-50 \mathrm{mls}$ may be given to some premature infants. As mentioned above, for newborn infants colostrum or breast milk may be collected in much smaller amounts and as little as $1 \mathrm{ml}$ may be fed to the infant if this is the total amount collected. The dilution factor will not then be as great as Vitali et al. suggest. Disinfectant undiluted by milk, may also remain on the outside of teats and the outside and inner areas of neonatal dummies.

In view of the above observations, if chemical disinfection is considered, the Working Group recommends that kits should be rinsed and dried after removal from the disinfectant. Particularly for susceptible infants, sterile water where available (Vitali et al., 2008) or cooled boiled water as recommended by some manufacturers, can be used for rinsing these items. Tanks or containers for the disinfectant need to be routinely washed, rinsed and dried every day as there may be a possibility that sodium salts could accumulate on the sides of the tanks.

\section{Decontamination of related articles}

Bottle brushes and breast/nipple shields. The Working Group recommends that these articles, if used, should be for use by one mother only. Between uses they should be decontaminated by the same methods used for breast pump milk collection kits.

Dummies (pacifiers, comforters or soothers) for infants on NNUs. Dummies may be required for some infants on NNUs for non-nutritive sucking. The Working Group considered that each dummy for infants on NNUs should be for the use of one infant only. The dummies should be securely and individually packed. They should also be new and ready to use without requiring decontamination before use. They should be discarded at least every 24 hours. When not in use during this time period, dummies that have been used should be stored in a clean, dry, container covered with fresh paper towels. If they become soiled or contaminated with anything other than the infant's saliva, they should be discarded immediately. There should be no attempt at decontaminating and reusing these dummies, either before or during use. This is because, for some dummies, the central bulb area (which is placed in the infant's mouth) is hollow and communicates through one or more small holes or vents with the outside surface of the dummy where it is handled. The hollow centre cannot be fully or easily accessed for decontamination. Varying amounts of detergents, disinfectants, organic material and micro-organisms may be retained within this hollow area. These substances can come out through the small holes and contaminate the outside surface of the dummy. The clinical relevance of this is uncertain but satisfactory decontamination of such dummies is not possible in practice. There are other types of dummies where the central bulb area is in direct and easy communication with the outside surface of the dummy, instead of communicating through small holes. All of the dummies reviewed so far by the Working Group for infants on NNUs have fallen into one or other of these two types. To ensure effective cleaning of the latter types of dummy, the bulb area would need to be inverted during the cleaning process. In some of these dummies inversion of the bulb is not possible and in others inversion results in the formation of recessed areas. These recessed areas lower the quality assurance of the cleaning, so that it is not acceptable for infants on NNUs.

\section{Conclusions}

Choice of a decontamination method for breast pump milk collection kits is dictated by practical considerations as well as by microbiological effectiveness. Such considerations include speed of the process, safety, convenience and cost. Kits have to be readily available as a mother may express milk eight or more times a day for up to several months. Also, mothers with an infant in hospital may express milk at home as well as in hospital, so methods of decontamination need to be considered in both places. Milk may also be expressed in the home for well infants for convenience, especially if the mother goes out to work.

The Working Group's recommendations are necessarily based mainly on good practice together with expert opinion. It is not possible to prevent some microorganisms getting into expressed breast milk. However, if the decontamination instructions in the Appendix are followed, any bacterial load should be reduced to acceptable levels. When correctly carried out, these processes should achieve appropriate decontamination in a practical time frame with readily available resources.

Although it is still the preferred method in some hospital units, the Working Group did not consider that it was essential to provide sterile breast pump milk collection equipment on each occasion milk is expressed by the same mother. This is an expensive method. If decontamination is carried out correctly and there is a good microbiological quality water supply for rinsing, it should not be necessary. All methods, including the standard wash, rinse and dry method, require appropriate training for each stage of the process, together with follow up instruction where needed.

Given the lower quality assurance of chemical disinfection compared to heat disinfection, the Working Group recommended that heat disinfection is the method of choice 
where disinfection is necessary. If a chemical disinfection method is considered for use for well infants in the home, mothers should be aware of the alternative methods available. Chemical disinfection may be considered for circumstances where the microbiological quality of the water is uncertain, as could occur with some private water supplies or in certain resource - poor countries. However, the points relating to chemical disinfection and the alternative methods mentioned above, should also be kept in mind.

With regard to the other items reviewed, the impossibility of adequately decontaminating dummies for infants on NNUs resulted in the Working Group recommendation that dummies for these infants should be discarded at least every $24 \mathrm{hrs}$. This is a new recommendation. The survey carried out by the Working Group showed that more than half of the units contacted still decontaminated these dummies by chemical methods. This could be a concern for this group of infants.

\section{Acknowledgements}

The authors wish to thank Anne Atkinson and Professor Dinah Gould for help and advice.

\section{Declaration of conflicting interests}

The author(s) declared no potential conflicts of interest with respect to the research, authorship, and/or publication of this article.

\section{Funding}

The author(s) received no financial support for the research, authorship, and/or publication of this article.

\section{Peer review statement}

Blind peer-reviewed.

\section{References}

Atkinson A. (2001) Decontamination of breast milk collection kits: a change in practice. Midwives Information Resource Services. Midwifery Digest 11(3): 381-383.

D'Amico CJ, DiNardo CA and Krystofiak S. (2003) Preventing contamination of breast pump kit attachments in the NICU. Journal of Perinatal and Neonatal Nursing 17(2): 150-157.
Department of Health. (2013) Water systems. Health Technical Memorandum 04-01: Addendum. Pseudomonas aeruginosa - advice for augmented care units. London: Department of Health.

Doxtator L and Zoutman D. (2006) Management of breast pump kits: a review. Canadian Journal of Infection Control 21: 92-95.

Gilks J, Gould D and Price E. (2007) Decontaminating breast pump collection kits for use on a on a neonatal unit. Review of current practice and literature. Journal of Neonatal Nursing 13: 191-198.

Gilks J, Price E, Hateley P, Gould D and Weaver G. (2012) Pros, cons and potential risks of on-site decontamination methods used on neonatal units for articles indirectly associated with infant feeding, including breast pump collection kits and neonatal dummies. Journal of Infection Prevention 13: 15-22.

Gransden WR, Webster M, French GL and Phillips I. (1986) An outbreak of Serratia marcescens transmitted by contaminated breast pumps in a special care baby unit. Journal of Hospital Infection 7: $149-154$.

Jones BL, Gorman LJ, Simpson J, Curran ET, McNamee S, Lucas C, Michie J, Platt DJ and Thakker B. (2001) An outbreak of Serratia marcescens in two neonatal intensive care units. Journal of Hospital Infection 49(4): 314-319.

Lucas A. (1977) Hypochlorite sterilising fluid as a source of dietary sodium in gavage-fed infants. Lancet 2(8029): 144-145.

Lui WF, Laudert S, Perkins B, MacMillan-York E, Martin S and Graven S for the NIC/Q 2005 Physical Environment Exploratory Group. (2007) The development of potentially better practices to support the neurodevelopment of infants in the NICU. Journal of Perinatology 27: S48-S93.

Moloney AC, Quoraishi AH, Parry P and Hall V. (1987) A bacteriological examination of breast pumps. Journal of Hospital Infection 9: 169-174.

Pittard WB, Geddes KM, Brown S, Mintz S and Hulsey TC. (1991) Bacterial contamination of human milk: container type and method of expression. American Journal of Perinatology 8(1): 25-27.

Price E, Awadel-Kariem FM, Hateley P, Gilks J and Kemply S. (2006) Possible hazards of hypochlorite disinfection for feeding equipment for premature infants. Journal of Hospital Infection 64: 90-92.

Royle J and Weaver G. (in press) Guidelines for the preparation and handling of expressed and donor breast milk and special feeds for infants and children in neonatal and paediatric healthcare settings. Birmingham: British Dietetic Association.

Shetty A, Barnes R, Adappa R and Doherty C. (2006) Quality control of expressed breast milk. Journal of Hospital Infection 62(2): 253-254.

Thom AR, Cole AP and Watrasiewicz K. (1970) Pseudomonas aeruginosa infection in a neonatal nursery possibly transmitted by a breast milk pump. Lancet 7646: 560-561.

Vitali M, Protano C and Angolini G. (2008) Advantages of sodium hypochlorite or sodium dichloroisocyanurate disinfection for teats and bottles in newborn infants' feeding. Public Health Nursing 25(2): 103-105. 


\section{Appendix}

\section{DECONTAMINATION RECOMMENDATIONS FROM A JOINT WORKING GROUP OF THE HEALTHCARE INFECTION SOCIETY AND THE INFECTION PREVEN- TION SOCIETY}

\section{Section A. Decontamination of breast pump milk collection kits}

1. General considerations

2. Guidance for routine cleaning of kits for reuse by one mother

3. Additional decontamination methods

4. Comments on hypochlorite based chemical disinfection for kits for reuse by one mother

\section{Section B. Decontamination of related items}

1. Bottle brushes

2. Breast/nipple shields

3. Dummies (pacifiers, comforters or soothers) used on neonatal units (NNUs)

Notes

I. All points listed below apply in both home and hospital, apart from those points that specifically refer to one or other situation.

II. In the home, clean kitchen roll may be used as an alternative to the paper towels used in hospital.

\section{Section A. Decontamination of breast pump milk collection kits}

\section{General considerations}

1.1. Kits should be discarded when no longer needed for use by the mother. They should not be passed on to another mother (unless they can be sterilized in a Sterile Services Department).

\subsection{Microbiological quality of the water}

- All places where mothers express their milk should have good microbiological quality water.

- For well infants in the home, potable (drinking quality) water should be used for rinsing the kits.

- In NNUs, the rinse water should be from outlets complying with Department of Health, Health Technical Memorandum 04-01 (2013) Water systems: Addendum Pseudomonas aeruginosa - advice for augmented care units. If the rinse water is not of an appropriately high microbiological quality, the use of sterile water for rinsing is advised.
1.3. In hospital, washing the kits should take place in a designated area approved by the Infection Prevention and Control Team (IPCT) and local department clinicians.

1.4. All decontamination methods should comply with the manufacturers' instructions, as long as these instructions are in accordance with locally agreed infection control policies.

1.5. For kits for reuse by one mother:

- Each mother should have her own breast pump milk collection kit or two kits for dual pumping where both breasts are expressed at the same time.

- Kits should not be shared with other mothers.

- After every use, the kits need to be decontaminated as detailed below (see A 2.3).

- Decontaminating the kits is usually carried out by the mother. Mothers should be given clear instructions by the relevant member of staff, using written and illustrated guidance.

- Staff should check that the mothers understand the importance of completely disassembling the breast pump milk collection kits, then thoroughly washing, rinsing and completely drying the individual parts (including the small \& more intricate pieces).

- Mothers should be aware that any part of the kit that remains wet could be a source of infection for the infant.

- Initial supervision of the decontamination process is recommended.

\section{Guidance for routine cleaning of the kits for reuse by one mother}

\section{I. Before first use}

2.1.1. In hospital, the kits should ideally be sterile. Where kits for hospital use are not sterile, they should be new and individually packaged by the manufacturer. They should be decontaminated according to the manufacturer's instructions; at minimum they should be detergent washed, rinsed and dried as detailed below.

NB Some hospitals use only sterile kits which are then discarded after use and a sterile replacement provided (see A 3.3.1).

2.1.2. In the home, kits should be new, individually packaged and sealed by the manufacturer. If they are not marked as sterile, they should be decontaminated according to the manufacturer's instructions; at minimum they should be detergent washed, rinsed and dried as detailed below.

\subsection{Before each use}

2.2.1. Before assembling the kit for use, wash hands, rinse thoroughly and dry with a paper towel. 


\subsection{After each use}

2.3.1. Clean kits as soon as possible after use to avoid milk residues sticking to surfaces.

2.3.2. Do not immerse the tubing between the collection kit and the pump in water. This tubing should remain dry during use. If it is splashed or dropped on the floor, the outside should be wiped over and dried with paper towels. If there is moisture within the tubing, it should be replaced.

\subsubsection{Dismantle the kit completely.}

2.3.4 Wash all parts of the kit using a clean bowl reserved for this purpose. Initially remove milk residues from the kit with water, drain and then use warm water and liquid detergent (one or two drops of the detergent is sufficient).

2.3.5. Rinse each part of the kit thoroughly with running water to remove detergent and any debris. Place the parts of the kit on paper towels on a clean dry surface.

2.3.6. Allow to air dry completely or dry all parts with paper towels. As far as possible, hollow parts should be inverted to allow draining. Do not use reusable cloth towels such as tea towels - these can have significant levels of bacterial contamination. Paper towels or kitchen roll should be stored in clean conditions, especially once opened.

2.3.7. The bowl used for washing the kits should also be washed, rinsed and dried after each use and stored dry.

2.3.8. The cleaned, disassembled kit should be stored dry in a clean, dry container covered with fresh paper towels to allow for complete drying of any undetected or inaccessible wet areas.

2.3.9. The storage container should be for the use of one mother only. It should be washed, rinsed and dried once a day.

2.3.10. If the storage container is sufficiently large, it could also be used as the washing bowl for these kits. This would save space and ensure that all components are kept together.

2.3.11. In hospital, the storage container should be marked with mother's name and hospital number to avoid any mixup with kits belonging to other mothers. Care should be taken that these details are not washed off.

2.3.12. Bottle brushes can be a source of contamination. Details on bottle brush use and decontamination are given at the end of this document (see section B 1)

\subsection{Dishwashing machines}

The kit may also be washed in a dishwashing machine.

2.4.1. As recommended by some manufacturers, the top shelf should be used on a $65-75^{\circ} \mathrm{C}$ cycle.

2.4.2. The kit should be fully dismantled. As far as possible, hollow items should be loaded inverted to allow drainage. A perforated container which holds the smaller dismantled parts and allows water to circulate around them is needed.
2.4.3. The washed kit should be removed from the dishwashing machine with clean hands, water should be shaken off all parts of the kit and they should be allowed to dry on paper towels/kitchen roll. Further drying with the paper towels may be necessary. The kit should be stored dismantled in a clean, dry container covered with paper towels as in 2.3.8.

2.4.4. In the home, the kit can be part of a normal dishwasher load and does not need to be washed separately. If the dishwashing machine is only used once a day, other decontamination procedures (usually wash, rinse and dry) will be needed at other times.

2.4.5. In hospital, dishwashing machines are not often used for decontaminating these kits. If used in hospital units, dishwashing machines should be dedicated to washing the kits. They should not be used for crockery and cutlery as well. A method of identifying individual pieces of equipment from specific mothers will be needed. The use of such a unit based dishwashing machine for this purpose should be approved for individual mothers by the local IPCT.

\section{Additional decontamination methods}

3.1 Depending on local risk assessments, additional decontamination methods may be used for certain infants on NNUs who are at high risk of infection, as determined by the departmental clinicians. They may also be indicated in situations where there is potential lack of compliance by the parents or carers with basic decontamination procedures.

3.2 Although the infant is in hospital, the mother may be expressing her milk at home as well as in hospital. The quality of the milk expressed at home is of equal importance to that of the milk expressed in hospital. The departmental clinicians and IPCT should advise on decontamination of kits in both places and the following options should be considered.

\subsection{Options for additional decontamination}

3.3.1. Use of sterile kits - these are either decontaminated and then autoclaved between use or purchased sterile and discarded after being used once.

3.3.2. For kits for reuse by one mother - an infant bottle disinfector that uses atmospheric pressure steam (free standing electrical units, or microwavable bowls or bags) may be used.

After expressing the milk, kits should be washed with detergent and rinsed before processing by atmospheric steam, then dried and stored dry. The manufacturer's instructions must be followed.

For all methods involving steam, care to avoid scalding is needed.

- If used, the microwavable bag may be dried with paper towels or left open as necessary so that it dries completely after use. It is designed to be used by only one mother - this reduces the risk of cross contamination and also the possibility that parts of kits from different 
mothers can become mixed up in hospital. It is possible to monitor the number of times the bags go through the steam process before needing to be discarded.

- For the free standing electrical units or microwavable bowls, water should be completely emptied out after each use and all parts thoroughly dried. There may be a risk of microbial growth if the equipment is not scrupulously dried after each use. Shared use in hospital may risk parts of kits from different mothers being mixed-up, so the equipment should only be used by one mother at each use. The individual kits should be identified as belonging to a particular mother.

- NB. Some mothers whose infants are well and at home, will opt to use an atmospheric pressure steam method. They should be told that this is an additional procedure and that they still need to wash and rinse the kit before using the steam producing equipment.

\section{Comments on hypochlorite based chemical disinfection for kits for reuse by one mother}

4.1. Chemical methods have lower quality assurance for disinfection than heat methods. Where disinfection is needed for susceptible infants, the Working Group recommends that heat disinfection is the method of choice and chemical disinfection should only be used if the local IPCT has given approval of the method and quality assurance of its use.

4.2. Dilute (i.e. in-use) hypochlorite is unstable and should be made-up fresh every day, taking care to measure liquids accurately.

4.3. Hypochlorites are highly susceptible to inactivation by organic matter; all items to be disinfected must be scrupulously clean. They should have been detergent washed and rinsed before immersion.

4.4. All items to be disinfected must be completely immersed for the period recommended by the manufacturer and be free of trapped air that would prevent contact between hypochlorite and all surfaces. Each mother should have her own allocated immersion tank which should be washed, rinsed and dried daily.

4.5. After disinfection, kits should be rinsed and dried. Especially for susceptible infants mentioned above, sterile water where available or cooled boiled water as recommended by some manufacturers, should be used for rinsing. (See comments under 'Chemical disinfection' in the main article).

\section{Section B. Decontamination of related items}

\section{Bottle brushes}

1.1 If a bottle brush is used, it should be new for each mother and should not be shared with other mothers. It should only be used for cleaning the breast pump milk collection kit and any associated bottles.

1.2. In hospital if bottle brushes are used, they should be suitably identified as belonging to that mother.

1.3. Bottle brushes should be detergent washed, rinsed in running water and thoroughly dried (ideally by squeezing in a clean dry paper towel) after every use and stored dry.

1.4. If bottle brushes are processed in a dishwashing machine or by an atmospheric pressure steam method (the latter after washing and rinsing), they should be thoroughly dried afterwards.

1.5. Bottle brushes should not be decontaminated with hypochlorite based disinfectants if they contain metals hypochlorite can be corrosive. If the brushes do not contain metals, they can be washed and immersed in hypochlorite, rinsed with good microbiological quality water (see above under section A 1.2). They should be dried thoroughly.

1.6. There is a risk of bacterial contamination if brushes are left wet.

1.7. Brushes should be discarded when no longer needed by the mother and not passed on to other mothers.

\section{Breast/nipple shields}

2.1. If used, these should be decontaminated by the same methods as are used for breast pump milk collection kits, usually detergent wash, rinse, dry and store dry.

2.2. They should be used by one mother alone and discarded when no longer required by that mother.

\section{Dummies (pacifiers, comforters or soothers) used on neonatal units (NNUs)}

3.1. Dummies may be needed for certain infants on NNUs for non-nutritive sucking. They should always be singleinfant use.

3.2. Manufacturers should provide the dummies ready-touse and securely individually packaged.

3.3. There should be no attempt at decontaminating the dummies either before use or during use.

3.4. They should be discarded every 24 hours. When not in use during this time period, they should be stored in a clean container covered with fresh paper towels. The container should be washed, rinsed and dried every day. If soiled or contaminated with anything other than the infant's saliva, the dummies should be discarded immediately.

(See further discussion in the accompanying text about the difficulty of decontaminating these dummies for use by infants on NNUs). 